\title{
A customer based supplier selection process that combines quality function deployment, the analytic network process and a Markov chain
}

\author{
Mehdi Rajabi Asadabadi \\ School of Business, UNSW, Australia \\ Published in European Journal of Operational Research \\ DOI: http://dx.doi.org/10.1016/j.ejor.2017.06.006
}

\begin{abstract}
:
The overall objective of this paper is to introduce a customer oriented supplier selection method. Although the supplier selection problem has previously been investigated, an effective solution to consider the dynamics of Customer Needs (CNs) in finding the best supplier has not yet been proposed. Such a method takes into account customer needs as a determinant factor in finding the best supplier and considers possible changes in the priorities of customer needs as time passes. In this study a method integrating the analytic network process (ANP), quality function deployment (QFD), and a Markov chain is used to address the supplier selection problem. This proposed method utilizes a Markov chain to trace the changing-priorities of customer needs and find a pattern for them. The ANP-QFD method then connects this pattern to product requirements (PRs) and PRs to supplier qualifications. This combination develops a customer based supplier selection method. The best supplier is selected based on the changing-priorities of customer needs. Although the customer needs priorities keeps changing, one supplier is selected as the best one. This study introduces an innovative customer based approach to select the best supplier that is independent of initial CNs.
\end{abstract}

Keywords: QFD; ANP; Markov Chain; Supplier Selection;

\section{Introduction}

Finding the best supplier is a critical factor for the prosperity of every company (Büyüközkan \& Göçer, 2017; Qin, Liu, \& Pedrycz, 2017). This decision significantly affects the overall performance of an organization (Ahmadi, Petrudi, \& Wang, 2016; Sampaio et al., 2016). In view of its significance (Govindan, Rajendran, Sarkis, \& Murugesan, 2015), multi-criteria decision making methods (MCDM) are developed to address difficulties in making such a decision (Chai, Liu, \& Ngai, 2013; Sodenkamp, Tavana, \& Di Caprio, 2016). The variety of methods used to address the supplier selection problem indicates the importance of the issue (Yazdani, Chatterjee, Zavadskas, \& Zolfani, 2017), but traditional approaches to finding the best supplier do not lead to an optimal ranking of suppliers (Govindan et al., 2015).

Although the supplier selection problem has been well investigated, only a few studies have proposed a customer based supplier selection approach. A review of the few studies shows none of them have proposed a method that considers the changing priorities of customer needs (CNs). Customer satisfaction is highly dependent on the quality of the final products and services (Goetsch \& Davis, 2014) insofar as quality is explained as what customers want (Nazari-Shirkouhi \& Keramati, 2017). The quality of products is highly affected by the quality of supplied raw materials or services (Chen \& Chen, 2006). Therefore, suppliers can be evaluated based on their impact on the quality of final products and services. The quality of final products and services has different aspects and parameters which influence the level of customer satisfaction. This satisfaction level is multi-criterial and depends on how well CNs are satisfied given the preferences and priorities. These preferences and priorities are subject to continuous change and a Markov chain is utilized to trace these. This process provides decision makers with an adjusted set of priorities. The new set acts as the input for the House of Quality (HOQ). The HOQ, the main tool of Quality Function Deployment (QFD), connects them to a set of product parameters (PRs) which is influenced by the supplied materials or services. The QFD method is equipped with the Analytic Network Process (ANP) to assure that interrelations are taken into account. Suppliers are ranked based on the effect of their products or services on the final product and so, ultimately on the level of customer satisfaction. Recently, Asadabadi (2016) has proposed a novel, Markovian ANP-QFD. The main contribution of this study is that it extends the model by establishing a customer based supplier selection approach that takes into account changing priorities of customer needs. Such an approach enhances the customer satisfaction while supporting a long term relationship with the selected supplier. Additionally, this paper validates the approach through a case study.

To cite this document: Asadabadi, M. R. (2017). A customer based supplier selection process that combines quality function deployment, the analytic network process and a Markov chain. European Journal of Operational Research, 263(3), 1049-1062. 
The remainder of the paper presents a review of the relevant literature. The method is illustrated utilizing a combination of the ANP, QFD, and a Markov chain to address the supplier selection problem. Then, the method is validated through addressing the supplier selection problem in a company. The paper ends with a brief discussion and a concluding section.

\section{QFD and HOQ}

Since the initial applications of the QFD method (Akao, 1972), it has become well-established in a variety of areas (Mehrjerdi, 2010). This method is considered as a powerful tool to translate customer needs into product requirements (Chen, Ko, \& Yeh, 2017; Haq \& Boddu, 2017; Sivasamy, Arumugam, Devadasan, Murugesh, \& Thilak, 2016). To do such a translation, the HOQ, the main tool of QFD, is applied (Liu, Hu, Zhang, \& Lei, 2017). This tool has shown a high level of flexibility where it is integrated with other tools and methods (Zare Mehrjerdi, 2010).

The HOQ is a simple matrix where customer needs: $\mathrm{CN}_{1}, \ldots, \mathrm{CN}_{\mathrm{n}}$ (n: number of identified CNs) are the rows and product requirements: $\mathrm{PR}_{1}, \ldots, P R_{m}$ (m: number of identified PRs) are the columns. PRs are determined by a QFDcross-functional-team (QFD-CFT) involving engineers, managers, and designers. Determining the relations and interrelations of the HOQ is a difficult process that is carried out by the same team (Chin, Wang, Yang, \& Poon, 2009).

If QFD were applied in different areas, customers could be kept happier by creating a customer oriented approach (Ayağ, Samanlioglu, \& Büyüközkan, 2013; Iqbal, P. Grigg, Govinderaju, \& Campbell-Allen, 2014; KutschenreiterPraszkiewicz, 2013). Such an approach contributes to achieving a higher level of customer satisfaction (Sharma \& Rawani, 2007; Georgiou et al., 2008) by employing an improved understanding of CNs (Mehrjerdi, 2010). CNs, obtained through interviews (Mehrjerdi, 2010), require further investigation before they are used as inputs to the HOQ (Chan \& Wu 2002). This requires further investigation on CNs in QFD.

\section{AHP and QFD}

The Analytic Hierarchy Process (AHP) is a MCDM method developed by Saaty (Saaty, 1977, 1986, 1990). This method performs pairwise comparisons between alternatives with respect to different criteria in order to make a decision (Mehrjerdi, 2010). Many researchers have utilized the AHP in combination with the QFD method to address different issues.

The AHP-QFD has been used to examine the impact of different teaching methods on student output (Lam \& Zhao, 1998), investigate the technical factors of robot selection (Bhattacharya, Sarkar*, \& Mukherjee, 2005), propose a framework for the tool selection problem (Hanumaiah, Ravi, \& Mukherjee, 2006), create an analytic approach for the concept of 'strategic service vision' (Partovi, 2001), address the prioritization problem of design requirements under resource limitations (Han, Chen, Ebrahimpour, \& Sodhi, 2001), design a knowledge management system for a semiconductor company in Taiwan (Chen, Yang, Lin, Yeh, \& Lin, 2007), take environmental factors into account in product design (Kuo \& Lin, 2012), guide the shipping investment decisions in the crude oil tanker market (Celik, Cebi, Kahraman, \& Er, 2009), address the material selection problem for vehicular structures (Mayyas et al., 2011), find the priorities of the student requirements based on course outcomes (Kamvysi, Gotzamani, Andronikidis, \& Georgiou, 2014), and address issues in many other areas. Since the ANP is basically built on some of the AHP fundamentals, to simplify understanding of the ANP AHP is briefly reviewed, based on Saaty (1994).

The AHP works by assigning importance weights to criteria. Then, the range of available options is examined to select the best one. The weights assigned to the criteria such as $W_{i j}$ are based on how important the $i^{\text {th }}$ element is, in comparison with the $\mathrm{j}^{\text {th }}$ element. If it is greater than one, the $\mathrm{i}^{\text {th }}$ element is more important than the $\mathrm{j}^{\text {th }}$ and vice versa. Satty's 9 point scale, Table 1, is applied in this research. This scale assigns 9 to the extremely important elements and this number decreases as the level of importance decreases. If $W_{i j}$ is, 7 , for example, we can conclude that, $W_{i j}$ is $1 / 7$ (this helps decision makers calculate a reciprocal matrix). If the conditions $a_{i j}=1 / a_{j i}, a_{i j}=\frac{a_{i k}}{a_{j k}}$ exist, the judgments are perfect and the comparison matrix is called consistent, but if not, the consistency test should be performed to determine whether the inconsistency level is tolerable (if it is above the tolerance, the comparisons should be improved or repeated).

Table 1: Saaty’s scale

To cite this document: Asadabadi, M. R. (2017). A customer based supplier selection process that combines quality function deployment, the analytic network process and a Markov chain. European Journal of Operational Research, 263(3), 1049-1062. 


\begin{tabular}{cc}
\hline \multicolumn{2}{c}{ The scale: Saaty's 9 point scale (Saaty, } \\
$\mathbf{1 9 8 6})$
\end{tabular}

Scores 2, 4, 6, and 8 indicate the amounts that are somewhere in between. The maximum principal eigenvalue in a reciprocal matrix is $\lambda_{\max }$. Since $\lambda_{\max }$ is substituted for the order of matrix (n) (refer to Saaty, 1986), its difference from $n$ is applied as an index: the closer to $n$, the more consistent the judgments. The consistency index (CI) is defined as:

$$
C I=\frac{\lambda_{\max }-n}{n-1} \quad \text { Eq. (1) }
$$

The principal eigenvalue of the matrix is compared with the principal eigenvalue of a random matrix (random index or RI): if the first is smaller than 10 percent of the second, the comparisons are approved (the perfect comparisons lead to $\mathrm{CR}=0$ ).

$$
C R=\frac{C I}{R I} \quad \text { Eq. (2) }
$$

The 'means' of random indexes are presented below and are based on simulated random pairwise comparisons.

Table 2: Consistency of random matrices (Saaty, 1990)

\begin{tabular}{lllllcll}
\hline Matrix order & $\mathbf{1}$ & $\mathbf{2}$ & $\mathbf{3}$ & $\mathbf{4}$ & $\mathbf{5}$ & $\mathbf{6}$ & $\ldots$ \\
\hline RI & 0 & 0 & 0.52 & 0.89 & 1.11 & 1.25 & $\ldots$ \\
\hline
\end{tabular}

Where the order of a matrix increases to more than three, the inconsistency is more likely to happen. This is because of the human's memory limitation in making consistent judgments when the number of the elements being compared increases (Miller, 1956).

Although the AHP is a capable selection method for multiple criteria situations (Marttunen, Lienert, \& Belton, 2017; Ahn, 2017), it suffers from a drawback namely its inability to consider interrelations of the elements. This motivates researchers to replace it with its developed version, the ANP (Saaty \& Takizawa, 1986; Satty, 1996, 1999).

\section{ANP and QFD}

The AHP considers a hierarchy of elements in a single direction. Saaty (Saaty, 1996, 1999) questioned this nature of the AHP and developed the ANP, a generalized form of the AHP, as a better alternative for MCDM problems. The ANP does not require a hierarchy, but rather a network of elements. In this network the elements are considered as nodes and a level of elements may both dominate and be dominated in comparison with the others (Partovi, 2001). When applying the ANP method, the final matrix is raised to an arbitrary large limiting power to obtain the cumulative effects of the elements on its interacted elements (Partovi, 2001; Satty, 1999).

To cite this document: Asadabadi, M. R. (2017). A customer based supplier selection process that combines quality function deployment, the analytic network process and a Markov chain. European Journal of Operational Research, 263(3), 1049-1062. 
The effectiveness of the ANP-QFD method has previously been examined in various areas. The method has been applied to investigate the satisfaction rate of soccer enthusiasts (Partovi \& Corredoira, 2002), take some factors such as cost budget and extendibility level into account in product design (Karsak, Sozer, \& Alptekin, 2003), determine and improve PRs in a PVC company (Kahraman, Cebeci, \& Ulukan, 2003), find a developed technique for process selection (Partovi, 2007), recognize the priority of engineering requirements for tooling fabrication (Pal, Ravi, \& Bhargava, 2007), deal with priorities of design elements of a new product (Iranmanesh \& Tabrizi, 2009), take the possibility of rapid changes of CNs into account in service (Adamcsek, 2008), find the proper importance level for a service context to improve commercial banking services (Kamvysi, Gotzamani, Georgiou, \& Andronikidis, 2010), identify the most important environmental requirement of production (Lin, Cheng, Tseng, \& Tsai, 2010), find the most effective design requirements in designing a sustainable SCM

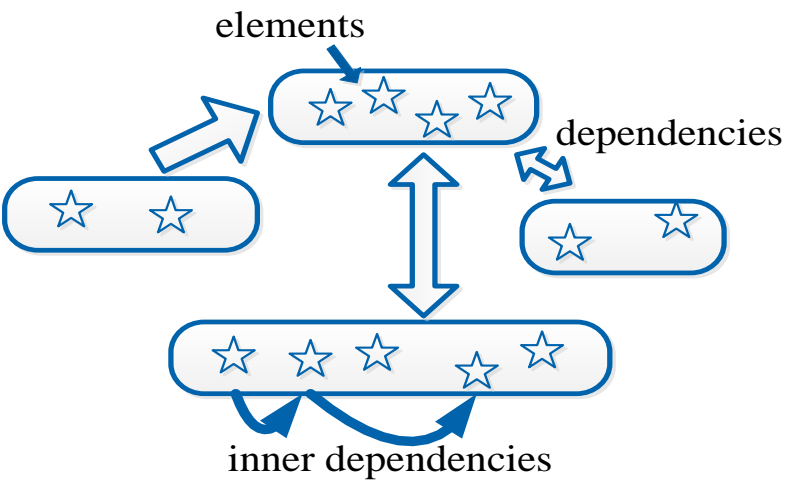
(Büyüközkan \& Berkol, 2011), and assess PRs considering risk control in green production (Lin, Lee, \& Kang, 2015).

A review of ANP as applied in this paper, is presented.

Fig. 1. Network structure

Then, along with previous applications of the ANP a network structure of elements is proposed (Fig. 1). Elements are categorized in clusters and inner and outer dependencies are taken into account. Thus, the elements in clusters can create a network instead of a hierarchy.

Assuming that each cluster: $\mathrm{k}, \mathrm{k}=1, \ldots, \mathrm{m}$, includes $\mathrm{n}_{\mathrm{k}}$ elements: $\mathrm{e}_{\mathrm{k} 1}, \ldots, \mathrm{e}_{\mathrm{kn}}$, the un-weighted supermatrix explained by Saaty (1996) is illustrated as below.



Matrix (1): The supermatrix

Matrix 1 assures that all the possible relations between the elements are considered. $\mathrm{W}_{\mathrm{ij}}$ represents the relations between cluster $i$ and $j$. Where $i$ is equal to $j$, the interrelations of the elements of the same cluster are demonstrated. This process can be applied throughout the HOQ to strengthen the applicability of QFD. Further, CNs, the inputs of QFD, can be evaluated and a pattern of the priority for CNs, following a Markov chain, can be offered to substitute the initial priorities.

\section{Customer Needs in QFD}

The main purpose of QFD is to achieve a higher level of customer satisfaction on the basis of CNs (Wang, 2012). a number of studies focus on the impact of CNs accuracy on the process of finding the priority of PRs or similar sets of elements (Asadabadi, 2016; Enriquez, Osuna, \& Bosch, 2004; Hsu \& Lin, 2006; Li \& Kuo, 2007; Okur, Nasibov, Kiliç, \& Yavuz, 2009; Raharjo, Brombacher, \& Xie, 2006, 2008; Raharjo, Xie, \& Brombacher, 2011; Sharma \& Rawani, 2007; Wang \& Chin, 2011; Wu, Liao, \& Wang, 2005). To deal with CN prioritization, Enriquez et al. (2004) To cite this document: Asadabadi, M. R. (2017). A customer based supplier selection process that combines quality function deployment, the analytic network process and a Markov chain. European Journal of Operational Research, 263(3), 1049-1062. 
apply a devised method, Wu et al. (2005) utilize the grey theory, Hsu et al. (2006) examine using the means-end theory, Raharjo et al. (2006) combine zero-one goal programming and a loss function, Li and Kuo (2007) adopt the genetic chaotic neural network technique, Sharma and Rawani (2007) use the weighted average method, Raharjo et al. (2008) propose a generic network model, Okur et al. (2009) apply the ordered weighted averaging technique, Wang and Chin (2011) apply linear goal programming (where customers are expressing their preference in different scales), and Asadabadi (2016) applies a Markov chain to find a pattern for CNs.

Raharjo et al. (2011) apply a combination of the AHP and QFD methods. In comparison with Raharjo et al. (2006) and (2008), Raharjo et al. (2011) emphasize the necessity of investigating and finding future CNs. They state that since it takes time to prepare a product, CNs may change when the product is finished. Therefore, the future CNs should be the basis of computations (Raharjo et al., 2006). Although the QFD method is inherently a customer focused product development approach, considering the importance of customer needs (Enriquez et al., 2004), which are the main inputs of the QFD approach, more studies are recommended to investigate CNs and propose new models. Such models can be examined to address problems such as the supplier selection problem.

\section{Markov Chains and QFD}

The efficiency of Markov chains in finding solutions to real world problems is well established (Liu, Chiu, \& Chiu, 2011; Pourmoayed, Nielsen, \& Kristensen, 2016; Baumann \& Sandmann, 2017). However, the application of Markov chains is relatively new to the applications of QFD method (Asadabadi, 2016) and has not been used to address the supplier selection problem. These chains have previously been applied to reduce the dependency on historical data in analyzing the demand and supply of the electricity market (Yu, Sheblé, \& Matos, 2006), deal with the 'credit risk associated with bank loans' (Lu, 2012), model multi-parameter processes to help equipment designs (Berthiaux, Marikh, Mizonov, Ponomarev, \& Barantzeva, 2004), compare three life cycle cost computing methods (Farran \& Zayed, 2009), identify the pattern of wind speed where the transition probabilities are made based on the historical data (Farran \& Zayed, 2009), present a rehabilitation policy for public infrastructure (Farran \& Zayed, 2009), predict the customer lifetime values for an auto repair company in Taiwan (Cheng, Chiu, Cheng, \& Wu, 2012), and address issues in many other areas. A review on the how a Markov chain works is presented.

A set of times $T=\left\{t_{0}, t_{1} \ldots, t_{m}\right\}$ and then a set of existing states $S=\left\{s_{1}, s_{2} \ldots, s_{n}\right\}$ are defined. Assuming that $\mathrm{p}_{\mathrm{ij}}$ denotes the probability of moving from state $\mathrm{s}_{\mathrm{i}}$ to state $\mathrm{s}_{\mathrm{j}}$, the matrix of the transition probabilities is:

$$
\mathrm{P}=\begin{gathered}
\mathrm{s}_{2} \\
\vdots \\
\mathrm{s}_{\mathrm{n}}
\end{gathered}\left[\begin{array}{cccc}
\mathrm{p}_{11} & \mathrm{p}_{12} & \cdots & \mathrm{p}_{1 \mathrm{n}} \\
\mathrm{p}_{21} & \vdots & \ddots & \vdots \\
\vdots & \ddots & \ddots & \vdots \\
\mathrm{p}_{\mathrm{n} 1} & \ldots & \ldots & \mathrm{p}_{\mathrm{nn}}
\end{array}\right] \quad \text { Matrix (2): The transition matrix }
$$

The probability of being at state $\mathrm{j}$ after $\mathrm{m}$ transitions where the starting state is state $\mathrm{i}$ can be computed as

$$
\mathrm{p}_{\mathrm{ij}}^{(\mathrm{m})}=\sum_{\mathrm{k}=1}^{\mathrm{n}} \mathrm{p}_{\mathrm{ik}} \mathrm{p}_{\mathrm{kj}} \quad \text { Eq. (3) }
$$

If the transition matrix is taken to power $\mathrm{k}, \mathrm{p}_{\mathrm{ij}}^{(\mathrm{k})}$ is located at row $\mathrm{i}$ and column $\mathrm{j}$ of that matrix. Therefore, the transition matrix after $\mathrm{k}$ periods is as below:

$$
\mathrm{P}^{\mathrm{k}}=\mathrm{s}_{2}\left[\begin{array}{cccc}
\mathrm{s}_{1} \\
\vdots
\end{array}\left[\begin{array}{cccc}
\mathrm{p}_{11}^{(\mathrm{k})} & \mathrm{s}_{2} & \cdots & \mathrm{s}_{\mathrm{n}} \\
\mathrm{s}_{\mathrm{n}} & \mathrm{p}_{12} & \cdots & \mathrm{p}_{1 \mathrm{n}}^{(\mathrm{k})} \\
\mathrm{p}_{21}^{(\mathrm{k})} & \vdots & \ddots & \vdots \\
\vdots & \ddots & \ddots & \vdots \\
\mathrm{p}_{\mathrm{n} 1}^{(\mathrm{k})} & \cdots & \cdots & \mathrm{p}_{\mathrm{nn}}^{(\mathrm{k})}
\end{array}\right]\right.
$$

Matrix (3): The transition matrix after k periods

To cite this document: Asadabadi, M. R. (2017). A customer based supplier selection process that combines quality function deployment, the analytic network process and a Markov chain. European Journal of Operational Research, 263(3), 1049-1062. 
Simple Markov chains are categorized as memory-less mathematical models (Singer, Helic, Taraghi, \& Strohmaier, 2014). To trace CN priorities, a Markov chain is applied to work as a predicting tool to model customer behaviors (De Cooman, Hermans, \& Quaeghebeur, 2009). The probabilities in Markov models can be very useful where the decision makers do not have much experience (Wu \& Shieh, 2008). The QFD method can be strengthened by applying some quantitative approaches such as the Markov chains (Jacques et al., 2009). The integration of the Markov chain and QFD has already been examined (Asadabadi, 2016; Wu \& Shieh, 2006, 2008). Wu and Shieh (2006, 2008) apply Markov chains on a AHP-QFD and Asdabadi (2016) extends this application to an ANP-QFD. This developed method can be utilized to address the supplier selection problem.

\section{Supplier Selection}

The effectiveness and efficiency of a company's performance, is negatively influenced by selecting a wrong supplier (W. Liu, Shen, \& Xie, 2017; Rao, Xiao, Goh, Zheng, \& Wen, 2017; Gölgeci, Murphy, \& Johnston, 2017). Since it is often impossible to find a supplier which is superior in all aspects (Karsak \& Dursun, 2015; Sampaio et al., 2016), tools and techniques are applied to assist the supplier selection decision (Sampaio et al., 2016). There are various criteria to select a supplier (Kumar Kar \& K. Pani, 2014). Chan et al. (2008) investigate the supplier selection problem where some criteria such as political situation, geographical location, performance history and risk factors are considered. Although quality, service, price, and delivery seem to be the frequently used criteria (Chan, Kumar, Tiwari, Lau, \& Choy, 2008; Kuo \& Lin, 2012; Viswanadham \& Samvedi, 2013), quality seems to be the most important (Wu, C et al., 2013; Ghorbani et al., 2013). Since quality is what customers want, this paper develops a customer based supplier selection utilizing QFD. The applicability of QFD to the process of supplier selection has been previously examined: QFD and data mining techniques ( $\mathrm{Ni}, \mathrm{Xu}$, \& Deng, 2007), the AHP and QFD (Bhattacharya, Geraghty, \& Young, 2010; Xie et al., 2011), and ANP and QFD (Bayazit, 2006). Both AHP-QFD and ANP-QFD are considered powerful ranking methods (Sivasamy et al., 2016). An ANP-QFD is capable of considering interrelations to select the best supplier.

Recently, Asadabadi (2016) has presented an innovative approach to trace the customer needs. The approach connects a Markov chain to the ANP-QFD. The needs of customers go through a Markov chain and finally a pattern of future customer needs is identified. The main purpose of this paper is to develop a customer based supplier selection approach but, since organization cannot frequently change suppliers and usually wish to support a long-term relationship in the supply chain, the best supplier is selected based on this pattern of customer needs.

\section{Methodology}

The approach proposed here utilizes a Markov chain to work in combination with ANP-QFD as a means of finding the best supplier. The Markov chain generates a pattern of $\mathrm{CN}$ priorities. This pattern is used as the main input of the ANP-QFD to find the priorities of PRs. The PR priorities are then utilized to rank suppliers inside a supermatrix.

Comparisons of the elements of QFD which include CNs, PRs, and suppliers, can be made based on the best available information gathered from interviews and meetings with customers and adjusted by a QFD-cross-functional team based on their knowledge, intuition, and experiences (Yahia, 2010). The method consists of the following steps:

1. Finding the pattern of $\mathrm{CN}$ priorities QFD is initiated with a list of $\mathrm{CN}$ priorities. The initial CN priorities are obtained through meetings with customers and can be ranked and adjusted by the managers or decision makers. These priorities may change and the initial $\mathrm{CN}$ priorities, especially for new products, may need further evaluation. Employing a Markov chain simplifies the process of finding the pattern of CNs. The Markov chain is capable of tracing frequent changes in order to find a pattern. Although this step of the method finds a pattern of CNs to be used instead of the initial CNs, this does not mean that customers are not changing their preferences. If each customer, or group of customers is monitored particularly, they change their preferences. But, in terms of the whole system, if the changes are traced, there are a certain number of customers with each of the CNs. Those numbers are computable using the Markov chain as follows. The initial priority list of CNs is normalized and presented in matrix $W_{C N}^{*}$.

To cite this document: Asadabadi, M. R. (2017). A customer based supplier selection process that combines quality function deployment, the analytic network process and a Markov chain. European Journal of Operational Research, 263(3), 1049-1062. 


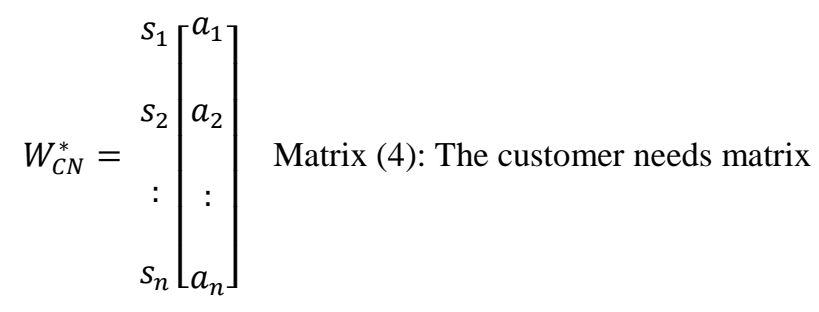

Assuming that at time zero, $a_{i}$ is greater than $a_{j}$ which means for example, more customers prefer and select $s_{i}$ $\left(i^{\text {th }} \mathrm{CN}\right)$ compared to $s_{j}\left(j^{\text {th }} \mathrm{CN}\right)$ as their most important need, undoubtedly, customer preferences change as well as the importance of the states. This results in changing the priorities and $s_{i}$ may not remain more than $s_{j}$ as time passes while the product is being developed. When the customers are buying or the company is selling the product in discrete times, a Markov chain can be applied more easily to model these changes. If a set of time: $\mathrm{T}=\left\{t_{0}, t_{1} \ldots, t_{m}\right\}$ is defined, there is always a likelihood of changing the preference from one $\mathrm{CN}$ to another after a period of time. In the above mentioned set of time, $t_{1}$ stands for the initial setting of the weights of customer preference, $t_{2}$ stands for the next time the customer buys the product and so on. The interval depends on how regularly customers approach buying the product and this varies for different product categories. While, for example, for a loaf of bread the interval can be every day or every other day, a grocery product can have the interval of a week. The weights of customers' preferences are obtained each time the customers approach buying the product. Note that in most industries it is more reasonable to make decisions based on the loyal customers' preferences rather than those of casual or occasional customers. Loyal customers tend to buy more often so it is easier to obtain their preferences. In the case of numerous customers, of course, sampling will be used.

The preferences of each customer may change each time the customer approaches buying the product. When having a reasonable sample of customers, it is possible to see the percentage of customers who have $\mathrm{CN}_{1}$ as their most important need and so wish to stay with $\mathrm{CN}_{1}$ or shift to other $\mathrm{CNs}\left(\mathrm{CN}_{2}, \mathrm{CN}_{3}, \ldots\right)$. These numbers are used to build the rows of the transition matrix (e.g., $\mathrm{p}_{11}, \mathrm{p}_{12}, \mathrm{p}_{13}, \ldots$ ) presented below as Matrix (5). CNs may be considered a set of states: $\mathrm{S}=\left\{s_{1}, s_{2} \ldots, s_{n}\right\}$. Assuming that $p_{i j}$ denotes the probability of moving from $\mathrm{i}^{\text {th }}$ state to $\mathrm{j}^{\text {th }}$ state, which is in fact changing the priority from $i^{\text {th }} \mathrm{CN}$ to $j^{\text {th }} \mathrm{CN}$, these probabilities can form a matrix here named the transition matrix.

Computing the transition matrix:

As mentioned above, customers' preferences may change each time they buy a product. This can be discerned from their choice of purchase from the product variety. It is assumed that the organisation can identify what the main customer preferences are by considering the features of their purchase choices. This helps the organisation recognise when customers' needs change. Note that these days, organizations are equipped with Information Communication Technologies (ICT) and initiatives such as customer membership cards, so it is easy to collect customer purchasing information which ultimately enables them to track their behaviour. Using such information, so called, big data provides us with the ability to measure the probability of transitioning from need $\mathrm{i}$ to $\mathrm{j}$ in $\mathrm{k}^{\text {th }}$ time, denoted by $p_{i j k}$. Fig. 2 provides an example of transitioning between four CNs (S1 to S4).

To cite this document: Asadabadi, M. R. (2017). A customer based supplier selection process that combines quality function deployment, the analytic network process and a Markov chain. European Journal of Operational Research, 263(3), 1049-1062. 


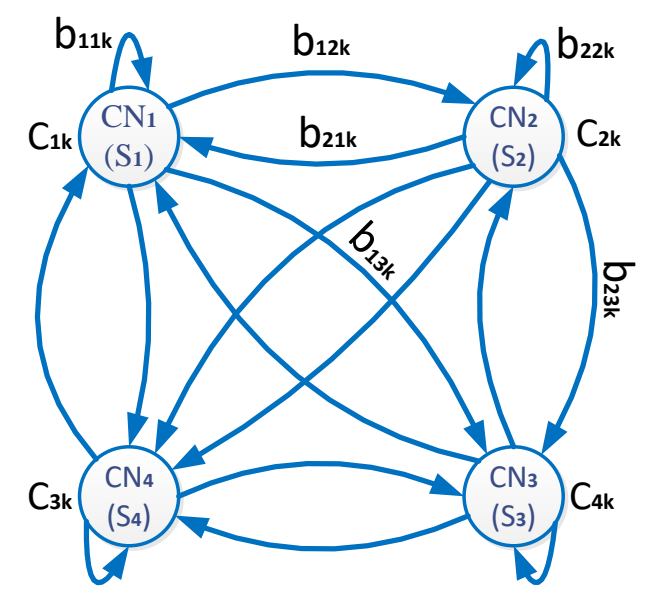

Fig. 2. Transitioning of $b_{i j}$ customers from $i^{\text {th }}$ to $j^{\text {th }} \mathrm{CN}$ at time $\mathrm{k}$

Assuming that there are $\mathrm{c}_{1 \mathrm{k}}$ customers who prefer $\mathrm{CN}_{1}$ at time $\mathrm{k}$, and $\mathrm{b}_{12 \mathrm{k}}$ are those who prefer to transition to $\mathrm{CN}_{2}$ at time $\mathrm{k}+1$, the probability of this transition is computed as: $p_{12 k}=\frac{b_{12 k}}{c_{1 k}}$. More generally, the probability of transitioning from state $i$ to state $j$ at time $k$ is:

$$
p_{i j k}=\frac{b_{i j k}}{c_{i k}} \quad \text { Eq. (4) }
$$

If after a specific time the following condition exists, the value of $p_{i j}$ in the transition matrix is equal to $\gamma_{i j}$ (note that $£$ stands for a small value).

$$
\left|p_{i j k}-\gamma_{i j}\right| \leq £ \quad \text { Eq. (5) }
$$

However, in many cases, it does not seem very practical to assume that after a time, a $\gamma_{i j}$ can be found that stays within a narrow interval such as $\left(\gamma_{i j}-£_{i j}, \gamma_{i j}+£_{i j}\right)$. But, different amounts for $\gamma_{i j}$ can instead be found that may stay valid for a reasonable period of time. To cope with such a situation, the managerial experts should set a number such that when the number of successive times that $\gamma_{i j}$ stays in the interval goes beyond that number, the transition matrix is computed and used until a new trend appears. The recognition of the trend, detection of the points of shifting $\gamma_{i j}$, and monitoring of the probabilities in the transition matrix can be performed using statistical quality control (SQC) techniques and charts (Xie, Goh, \& Kuralmani, 2012) associated with change point detection techniques (Brodsky \& Darkhovsky, 2013).

As discussed, when the sequence $\left\{P_{i j k}\right\}$ is relatively close to $\gamma_{i j}$, the value of $p_{i j}$ is estimated by $\gamma_{i j}$. Since the method has a high level of robustness and the transition matrix includes $n^{2}$ values presented by $p_{i j}$, small changes in the values of $p_{i j}$ do not seem to have any significant impact on the final results. Since further discussion of this matter is beyond the scope of the paper, here only a simple threshold is considered. If a highly accurate results are needed, a strict policy would consider any change of the probabilities that goes beyond 0.05 as the point that requires recalculation of the transition matrix. A milder approach, and recommended here, is to set the threshold for the average of the absolute changes (Eq. (5)) in the probabilities of the transition matrix instead of considering each separately.

Given the above concerns, the transition matrix is computed as follows.

To cite this document: Asadabadi, M. R. (2017). A customer based supplier selection process that combines quality function deployment, the analytic network process and a Markov chain. European Journal of Operational Research, 263(3), 1049-1062. 


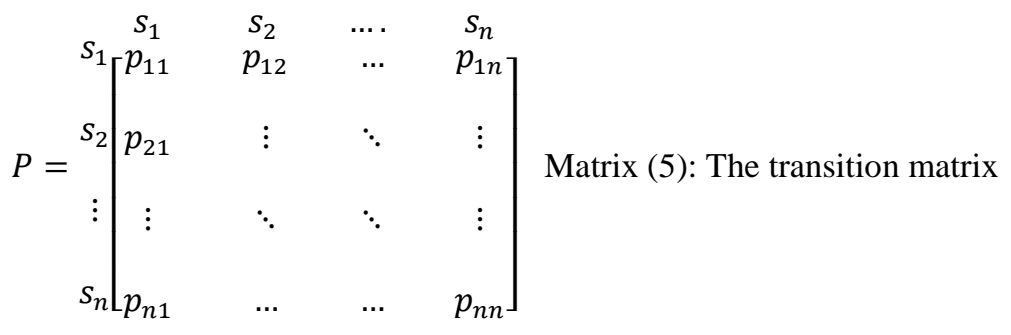

By frequently multiplying the transpose of matrix $W_{C N}$ by the transition matrix, $\mathrm{P}$, a set of $W_{C N}^{(i)}$ is calculated as follows ( $\mathrm{i}$ is the number of the multiplications based on which the matrix is computed):

$$
W_{C N}^{(0)^{T}}=W_{C N}^{T} I, W_{C N}^{(1)^{T}}=W_{C N}^{T} P^{1}, \ldots, W_{C N}^{(i)}{ }^{T}=W_{C N}^{T} P^{i} \quad \text { Eq. (6) }
$$

The more general form of the formula is:

$$
W_{C N}^{(k)}{ }^{T}=W_{C N}^{T} P^{k}, \quad \forall k=0,1, \ldots, \infty \quad \text { Eq. (7) }
$$

For each step, this formula results in a priority set of PRs and a ranking of suppliers. The inherent convergence of the stochastic matrices results in the same matrices after three to five multiplications (steps). The model can be generalized by using the adjusted $\mathrm{CN}$ priorities after several iterations of multiplication by the transition matrix. Since the adjusted priorities of CNs are independent of the initial state (Markov concepts), this method stands independent of the initial priorities of CNs. Thus, forming the transition matrix should be enhanced rather than identifying the customers' initial (instant) needs.

By raising $\mathrm{P}$ to a large power, the limiting matrix is found where the arrays in each column are the same. Multiplying the initial matrix or the matrix of instant customer needs by this limiting matrix leads to the same matrix regardless of the initial matrix (considering that $W_{C N}^{*}$ must be normalized). Therefore, in this method there is no need to obtain the initial CNs. The calculated matrix (after the multiplications) which is not being changed anymore is matrix $W_{C N}$ of the supermatrix (see the supermatrix presented after these steps).

Note that the method does not guarantee that the same pattern remains untouched over time, but the pattern does stay the same while there is no major change in probabilities of the transition matrix. However, due to the frequent multiplication of matrices, this method has reached a level of robustness and is not affected by minor changes. Each time that the probabilities are computed through interviews, the decision maker can update the transition matrix and the method (software based) performs the computations. If the new information does not change the sequence of the alternatives, there is no concern. But if change does occur, then the decision maker has to decide when to shift from the current supplier to a new supplier, while taking into account other important factors such as obtained trust and effort needed for new negotiations. After finding the pattern of CNs, the relations and inter-relations between $\mathrm{CNs}$ and PRs need to be computed.

\section{Finding interrelations of $\mathrm{CNs}$}

These interrelations can be found by asking simple questions such as: 'what is the relative importance of the $\mathrm{i}^{\text {th }} \mathrm{CN}$ when compared to the $\mathrm{j}^{\text {th }} \mathrm{CN}$ with respect to the $\mathrm{k}^{\text {th }} \mathrm{CN}$ ?' For example, when there are four $\mathrm{CNs}$ as follows: 'performance', 'reliability', 'serviceability', and 'cost of maintenance', such a question could be: what is the importance of reliability when compared to serviceability considering the cost of maintenance?

CNs are compared with one another with respect to each $\mathrm{CN}$ in separate tables. The calculated importance weights are used to calculate matrix $W_{C N-C N}$ of the supermatrix.

\section{Identifying PRs}

To cite this document: Asadabadi, M. R. (2017). A customer based supplier selection process that combines quality function deployment, the analytic network process and a Markov chain. European Journal of Operational Research, 263(3), 1049-1062. 
A list of PRs is made taking into account the product specifications. Such a list could be obtained by having meetings with engineers and designers to find a suitable list of PRs.

4. Finding the interrelations of PRs

A similar approach to step two is applied to obtain the interrelations of PRs and the result is matrix $W_{P R-P R}$.

5. Determining internal relations of suppliers

A similar approach to step two (or four) is applied to compare suppliers with respect to each to calculate $W_{S-S}$ of the supermatrix.

6. Determining the relations between the elements

The intensity of the relations between PRs is evaluated and compared with respect to each CN, so that if there are ' $n$ ' CNs, ' $n$ ' tables are needed. In each table, PRs are compared with respect to one of the CNs. The importance of PRs with respect to each $\mathrm{CN}$ is computed and moved to the relevant column of a new matrix named $W_{\mathrm{PR}-\mathrm{CN}}$. A similar approach is used to form $W_{S-P R}$.

Following the above steps, the super matrix discussed by Saaty (1999) is obtained.

\begin{tabular}{|c|c|c|c|c|c|c|}
\hline \multirow{4}{*}{$\mathrm{W}=$} & & Goal & CNs & PRs & Suppliers & \multirow{5}{*}{ Matrix (6): The supermatrix } \\
\hline & Goal & {$[0$} & 0 & 0 & $\begin{array}{ll}0 & 1\end{array}$ & \\
\hline & CNs & $W_{C N}$ & $W_{C N-C N}$ & 0 & 0 & \\
\hline & PRs & 0 & $W_{P R-C N}$ & $W_{P R-P R}$ & 0 & \\
\hline & plie & 0 & 0 & $W_{S-P R}$ & $\left.W_{S-S}\right\rfloor$ & \\
\hline
\end{tabular}

In this supermatrix $W_{C N-C N}, W_{P r-P R}$, and $W_{S-S}$ represent internal dependencies of CNs, PRs, and suppliers. $W_{C N}$ represents $\mathrm{CN}$ priorities obtained in step one. $W_{P R-C N}$ represents the relations between PRs and CNs without considering internal relations. $W_{S-P R}$ represents the simple relations between suppliers and PRs. Except $W_{C N}$, all the matrices require several tables. To find the best supplier, additional calculations are required as follows.

1. Computing the relations between PRs and CNs considering interdependencies of PRs:

$$
W_{A}=W_{P R-P R} \cdot W_{P R-C N} \quad \text { Eq. (8) }
$$

2. Computing the relations between suppliers and PRs considering interdependencies of suppliers:

$$
\mathrm{W}_{\mathrm{B}}=\mathrm{W}_{\mathrm{S}-\mathrm{S}} \cdot \mathrm{W}_{\mathrm{S}-\mathrm{PR}} \quad \text { Eq. (9) }
$$

3. Computing $\mathrm{CN}$ priorities considering their interdependencies:

$$
W_{C}=W_{\mathrm{CN}-\mathrm{CN}} \cdot W_{\mathrm{CN}} \quad \text { Eq. }(10)
$$

4. Computing PR priorities considering their interdependencies and the CNs interdependencies based on $\mathrm{CN}$ priorities:

$$
W_{D}=W_{A} \cdot W_{C} \quad \text { Eq. (11) }
$$

5. Ranking suppliers considering all the relations and interrelations between all the involved elements:

$$
W_{A N P}=W_{B} \cdot W_{D} \quad \text { Eq. (12) }
$$

The applicability of the method has been examined in a company, as discussed in the next section.

\section{An Illustrative Example}

Absal-Jam Co. is a manufacturer of water based air coolers in Iran. This kind of cooler takes advantage of the evaporation of water to cool the air. An important component of the cooler is the blower motor which is supplied to To cite this document: Asadabadi, M. R. (2017). A customer based supplier selection process that combines quality function deployment, the analytic network process and a Markov chain. European Journal of Operational Research, 263(3), 1049-1062. 
the factory. The company has been selecting the motor supplier subjectively based on the quality and price of the motors, but the company is now determined to employ a systematic approach to find the best supplier based on customer desires. The customer based supplier selection method explained in the previous section is applied to find the best supplier from a list of four potential motor suppliers. To keep their true identities confidential, suppliers are named supplier A, B, C, and D. The potential suppliers have agreed to let the company gather the required information for the selection process.

A recent study has revealed that the customer needs for the final product are: performance, reliability, price, serviceability, noise and cost of maintenance. The important parameters determining the quality of the supplied blower motors are: the manufacturing process and technology, output, reparability, raw materials, tolerance and fuel consumption. Following the steps of the method, the matrices are calculated as below.

\section{Obtaining $W_{C N}$}

As mentioned previously, CNs very likely will change. Considering step one of the method, the discussed transition matrix is computed as given below. From this, $W_{C N}$ for the supermatrix is easy to compute.

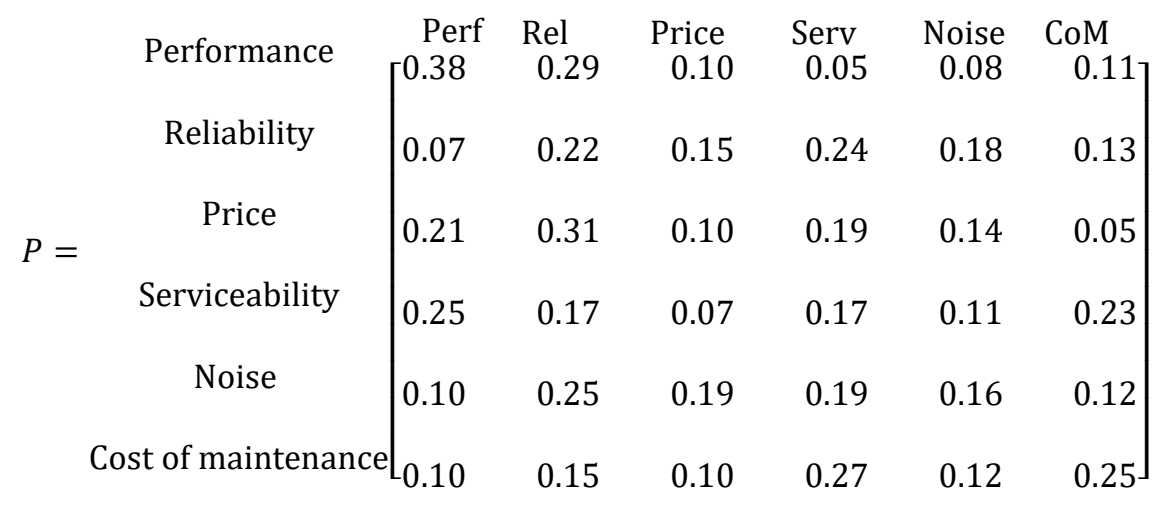

Matrix (7): The transition matrix

The initial $\mathrm{CN}$ priorities are obtained as below:

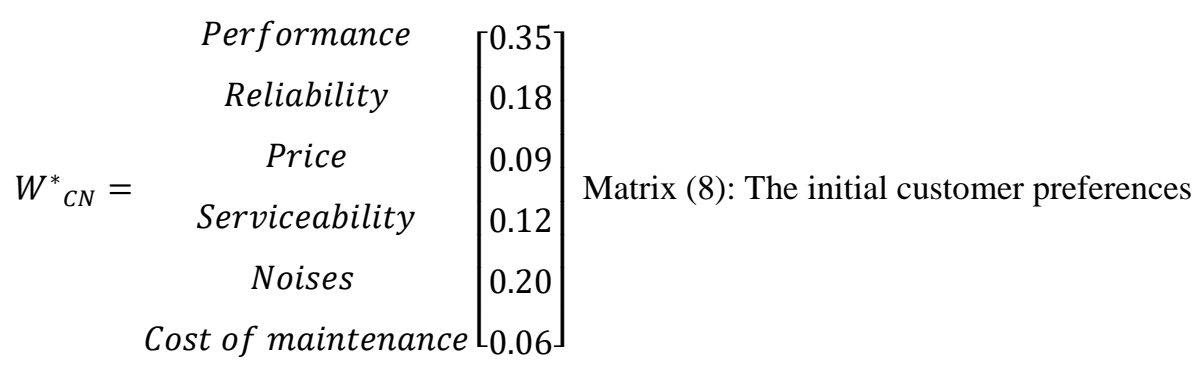

Based on the above two matrices, the following matrices are calculated.

\begin{tabular}{|c|c|c|c|c|c|c|}
\hline$W_{C N}^{(0)^{T}}=$ & $\begin{array}{l}\text { Perf } \\
{[0.222}\end{array}$ & $\begin{array}{c}\text { Relia } \\
0.248\end{array}$ & $\begin{array}{c}\text { Price } \\
0.122\end{array}$ & $\begin{array}{r}\text { Serv } \Lambda \\
0.151\end{array}$ & $\begin{array}{l}\text { Ioises } \\
0.124\end{array}$ & $\begin{array}{r}\text { Cost of } \\
0.133]\end{array}$ \\
\hline$W_{C N}^{(1)^{T}}=$ & {$[0.192$} & 0.233 & 0.118 & 0.178 & 0.132 & 0.147 \\
\hline$W_{C N}^{(2)^{T}}=$ & {$[0.188$} & 0.229 & 0.118 & 0.182 & 0.132 & 0.152 \\
\hline$W_{C N}^{(i)^{T}}=$ & {$[0.187$} & 0.228 & 0.117 & 0.183 & 0.132 & 0.153] \\
\hline
\end{tabular}

The limiting transition matrix is obtained by raising the transition matrix to a large power.

To cite this document: Asadabadi, M. R. (2017). A customer based supplier selection process that combines quality function deployment, the analytic network process and a Markov chain. European Journal of Operational Research, 263(3), 1049-1062. 


$P_{\text {limiting }}=\left[\begin{array}{cccccc}0.187 & 0.228 & 0.117 & 0.183 & 0.132 & 0.153 \\ 0.187 & 0.228 & 0.117 & 0.183 & 0.132 & 0.153 \\ 0.187 & 0.228 & 0.117 & 0.183 & 0.132 & 0.153 \\ 0.187 & 0.228 & 0.117 & 0.183 & 0.132 & 0.153 \\ 0.187 & 0.228 & 0.117 & 0.183 & 0.132 & 0.153 \\ 0.187 & 0.228 & 0.117 & 0.183 & 0.132 & 0.153\end{array}\right]$

Matrix(9): The limiting matrix

As mentioned in the first step of the method, regardless of the initial CN priorities, $W_{C N}$ is obtained as displayed below.



2. Obtaining $W_{C N-C N}$

The interdependencies of the customer needs are identified by pairwise comparisons with respect to each of them. Responding to questions such as: 'What is the relative importance of the $\mathrm{i}^{\text {th }} \mathrm{CN}$ compared to the $\mathrm{j}^{\text {th }} \mathrm{CN}$ considering

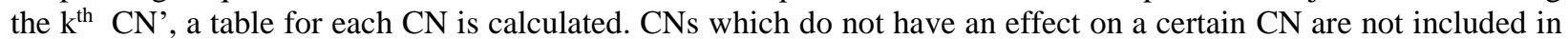
the table of that CN. The provided abbreviations are as follows, Performance: Perf; Reliability: Rel; Serviceability: Serv; Cost of Maintenance: CoM; and Importance eigenvector: Weights.

Table 3: CN comparisons with respect to performance

\begin{tabular}{llllllll}
\hline Perf & Perf & Rel & Price & Serv & Noise & CoM & Weights \\
\hline Perf & 1 & 3 & 2 & 5 & 3 & 4 & 0.376 \\
Rel & $1 / 3$ & 1 & 1 & 2 & 1 & 2 & 0.149 \\
Price & $1 / 2$ & 1 & 1 & 3 & 2 & 2 & 0.192 \\
Serv & $1 / 5$ & $1 / 2$ & $1 / 3$ & 1 & $1 / 2$ & 1 & 0.071 \\
Noise & $1 / 3$ & 1 & $1 / 2$ & 2 & 1 & 2 & 0.133 \\
CoM & $1 / 4$ & $1 / 2$ & $1 / 2$ & 1 & $1 / 2$ & 1 & 0.079 \\
\cline { 1 - 3 } $\boldsymbol{\lambda} \mathbf{6 . 0 5 9}$ & & CI:0.012 & CR:0.009 & & \\
\hline
\end{tabular}

The above table has been formulated with respect to performance. Five more tables are computed that compare CNs among themselves and the eigenvector (weights) for each $\mathrm{CN}$ is used to calculate $W_{C N-C N}$, which is later placed in the supermatrix.

To cite this document: Asadabadi, M. R. (2017). A customer based supplier selection process that combines quality function deployment, the analytic network process and a Markov chain. European Journal of Operational Research, 263(3), 1049-1062. 


$$
\begin{aligned}
& \text { Perf Relia Price Serv Noise CoM } \\
& \begin{array}{r}
\text { Perf } \\
\text { Rel }
\end{array} \quad\left[\begin{array}{llllll}
0.376 & 0.235 & 0.373 & 0.115 & 0.230 & 0.167 \\
0.149 & 0.118 & 0.187 & 0.230 & 0.070 & 0.096 \\
& \text { Serv } \\
\text { Noise } & \text { CoM }
\end{array}\left[\begin{array}{llllll}
0.192 & 0.118 & 0.187 & 0.053 & 0.121 & 0.301 \\
0.071 & 0.235 & 0.098 & 0.257 & 0.230 & 0.103 \\
0.133 & 0.235 & 0.057 & 0.115 & 0.230 & 0.050 \\
0.079 & 0.059 & 0.098 & 0.230 & 0.121 & 0.283
\end{array}\right]\right.
\end{aligned}
$$

Next, the interdependencies of PRs are dealt with.

\section{Obtaining $W_{P R-P R}$}

The interdependencies of PRs are determined by performing pairwise comparisons with respect to each PRs. The approach is very similar to what was done to obtain $W_{C N-C N}$. Those PRs which do not affect a PR are not included in its table. The abbreviations below are used throughout the paper: Process and Technology: P\&T; Tolerance: Toler; Replace-ability of components: Rep; Used Raw Materials: Used RM; and Consumption: Cons.

Table 4: PR comparisons with respect to P\&T

\begin{tabular}{llllllll}
\hline P\&T & P\&T & Toler & Output & Rep & Used RM & Cons & Weights \\
\hline P\&T & 1 & 2 & $1 / 2$ & 7 & 2 & 3 & 0.238 \\
Toler & $1 / 2$ & 1 & $1 / 4$ & 2 & 1 & 2 & 0.111 \\
Output & 2 & 4 & 1 & 8 & 4 & 6 & 0.425 \\
Rep & $1 / 7$ & $1 / 2$ & $1 / 8$ & 1 & $1 / 2$ & 1 & 0.052 \\
Used RM & $1 / 2$ & 1 & $1 / 4$ & 2 & 1 & 2 & 0.111 \\
Cons & $1 / 3$ & $1 / 2$ & $1 / 6$ & 1 & $1 / 2$ & 1 & 0.062 \\
\hline $\boldsymbol{\lambda}: \mathbf{6 . 0 5 8}$ & & CI: 0.012 & & & CR: 0.009 & \\
\hline
\end{tabular}

Five other tables compare PRs with respect to the other PRs and the result is the below matrix.

$$
\begin{aligned}
& \text { P\&T Toler Output Rep Used RM Cons } \\
& \begin{array}{c}
\text { P\&T } \\
\text { Toler } \\
\text { Rep } \\
\text { Used RM } \\
\text { Cons }
\end{array}\left[\begin{array}{llllll}
0.238 & 0.342 & 0.238 & 0.182 & 0.124 & 0.140 \\
0.111 & 0.171 & 0.000 & 0.048 & 0.124 & 0.081 \\
0.425 & 0.000 & 0.463 & 0.334 & 0.234 & 0.520 \\
0.052 & 0.342 & 0.119 & 0.334 & 0.124 & 0.000 \\
0.111 & 0.054 & 0.119 & 0.102 & 0.395 & 0.000 \\
0.062 & 0.091 & 0.061 & 0.000 & 0.000 & 0.260
\end{array}\right] \\
& \text { Matrix (12): PR interdependencies }
\end{aligned}
$$

To cite this document: Asadabadi, M. R. (2017). A customer based supplier selection process that combines quality function deployment, the analytic network process and a Markov chain. European Journal of Operational Research, 263(3), 1049-1062. 
4. Obtaining $\mathrm{W}_{\mathrm{S}-\mathrm{S}}$

To obtain $\mathrm{W}_{\mathrm{S}-\mathrm{S}}$, all suppliers are pair-wisely compared with respect to each one of them.

Table 5: Supplier comparisons with respect to supplier A

\begin{tabular}{llllll}
\hline Supplier A & Supplier A & Supplier B & Supplier C & Supplier D & Weights \\
\hline Supplier A & 1 & 1 & 2 & 1 & 0.286 \\
Supplier B & 1 & 1 & 2 & 1 & 0.286 \\
Supplier C & $1 / 2$ & $1 / 2$ & 1 & $1 / 2$ & 0.143 \\
Supplier D & 1 & 1 & 2 & 1 & 0.286 \\
\cline { 1 - 4 } $\boldsymbol{\lambda} \mathbf{4 . 0 0 0}$ & & CI: 0.000 & & CR: 0.000 & \\
\hline
\end{tabular}

Table 5 presents the comparisons with respect to Supplier A. With respect to the other three suppliers, three other tables can be computed and from their last columns, $W_{S-S}$ is obtained.

Sup A Sup B Sup C Sup D

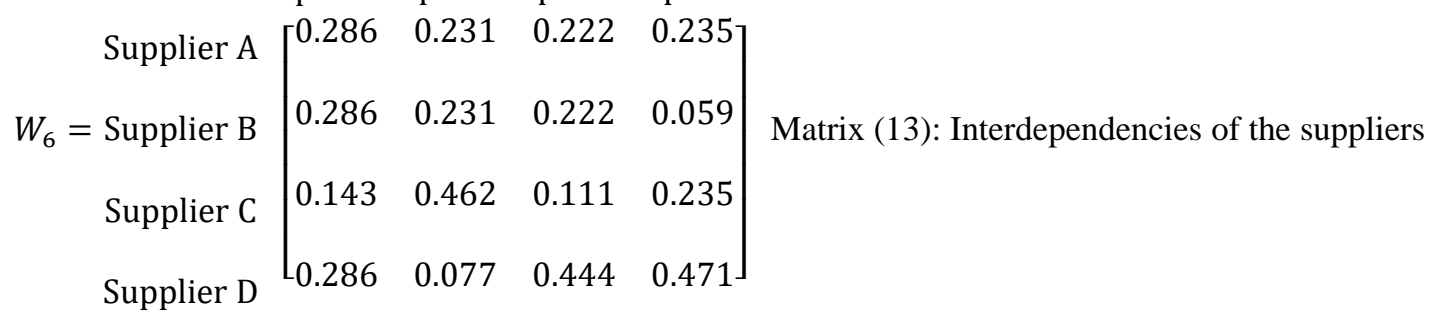

5. Obtaining $\mathrm{W}_{\mathrm{PR}-\mathrm{CN}}$

$\mathrm{W}_{\mathrm{PR}-\mathrm{CN}}$ is a matrix representing the relations between CNs and PRs. Assuming there are no interdependencies among PRs, they are subjected to pairwise comparisons with respect to each of the CNs. A question to ask that will help these comparisons is: how important is the $\mathrm{i}^{\text {th }} \mathrm{PR}$ in comparison with the $\mathrm{j}^{\text {th }} \mathrm{PR}$ with respect to the $\mathrm{k}^{\text {th }} \mathrm{CN}$. The responses result in tables such as Table 6.

Table 6: PR comparisons with respect to reliability

\begin{tabular}{llllll}
\hline Rel & P\&T & Toler & Rep & Used RM & Weights \\
\hline P\& T & 1 & 2 & $1 / 2$ & 3 & 0.261 \\
Toler & $1 / 2$ & 1 & $1 / 4$ & 1 & 0.119 \\
Rep & 2 & 4 & 1 & 6 & 0.523 \\
Used RM & $1 / 3$ & 1 & $1 / 6$ & 1 & 0.097 \\
\cline { 1 - 4 } $\boldsymbol{\lambda : 4 . 0 2 1}$ & & CI: 0.007 & & CR: 0.008 & \\
\hline
\end{tabular}

PRs with respect to the other five $\mathrm{CNs}$ are compared and considering in terms of their eigenvectors, $W_{P R-C N}$ is calculated as below.

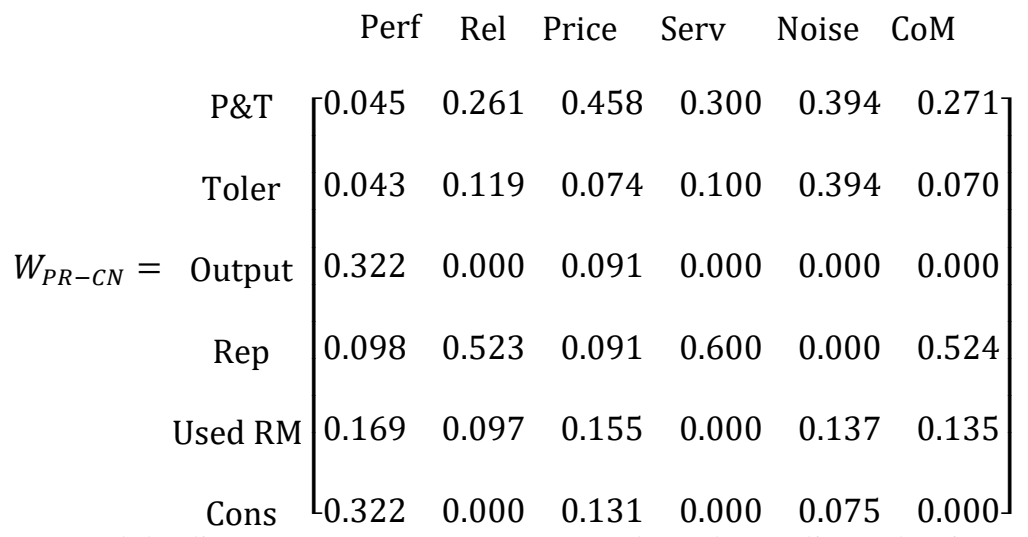

To cite this document: Asadabadi, M. R. (2017). A customer based supplier selection process that combines quality function deployment, the analytic network process and a Markov chain. European Journal of Operational Research, 263(3), 1049-1062. 
6. Obtaining $\mathrm{W}_{\mathrm{S}-\mathrm{PR}}$

Matrix (14): Relations between CNs and PRs

The same approach used to obtain $\mathrm{W}_{2}$ is applied to compare suppliers with respect to each PR. One of the six resulting tables is presented here as Table 7.

Table 7: Supplier comparisons with respect to P\&T

\begin{tabular}{llllll}
\hline P\&T & Supplier A & Supplier B & Supplier C & Supplier D & Weights \\
\hline Supplier A & 1 & 2 & 2 & 1 & 0.333 \\
Supplier B & $1 / 2$ & 1 & 1 & $1 / 2$ & 0.167 \\
Supplier C & $1 / 2$ & 1 & 1 & $1 / 2$ & 0.167 \\
Supplier D & 1 & 2 & 2 & 1 & 0.333 \\
\cline { 1 - 4 } $\boldsymbol{\lambda} \mathbf{4 . 0 0 0}$ & \multicolumn{2}{c}{ CI:0.000 } & CR: 0.000 & & \\
\cline { 1 - 3 }
\end{tabular}

The results are used to calculate $W_{S-P R}$.

$$
\begin{aligned}
& \text { P\&T Toler Output Rel Used RM Cons }
\end{aligned}
$$

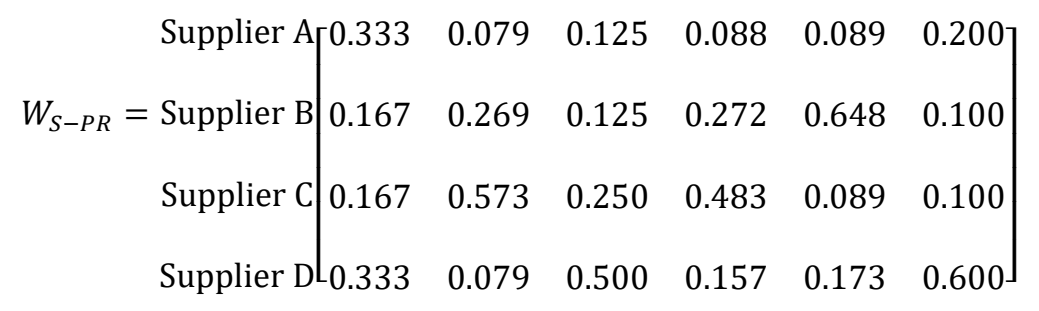

The obtained matrices are then placed in a larger matrix to calculate the supermatrix.

7. The supermatrix

The supermatrix is calculated as below.

To cite this document: Asadabadi, M. R. (2017). A customer based supplier selection process that combines quality function deployment, the analytic network process and a Markov chain. European Journal of Operational Research, 263(3), 1049-1062. 
$\mathrm{W}=$

\begin{tabular}{|c|c|c|c|c|c|c|c|c|c|c|c|c|c|c|c|c|c|}
\hline Goal & $\begin{array}{l}\text { Goal } \\
{\left[\begin{array}{l}0\end{array}\right.}\end{array}$ & $\begin{array}{l}\text { Perf } \\
0.000\end{array}$ & $\begin{array}{c}\text { Rel } \\
0.000\end{array}$ & $\begin{array}{l}\text { Price } \\
0.000\end{array}$ & $\begin{array}{c}\text { Serv } \\
0.000\end{array}$ & $\begin{array}{l}\text { Noise } \\
0.000\end{array}$ & $\begin{array}{c}\text { CoM } \\
0.000\end{array}$ & $\begin{array}{c}P \& T \\
0.000\end{array}$ & $\begin{array}{l}\text { Toler } \\
0.000\end{array}$ & $\begin{array}{c}\text { Output } \\
0.000\end{array}$ & $\begin{array}{c}\text { Rep } \\
0.000\end{array}$ & $\begin{array}{l}\text { Us RM } \\
0.000\end{array}$ & $\begin{array}{c}\text { Cons } \\
0.000\end{array}$ & $\begin{array}{c}\text { Sup A } \\
0.000\end{array}$ & $\begin{array}{r}\text { Sup B } \\
0.000\end{array}$ & $\begin{array}{l}\text { Sup } C \\
0.000\end{array}$ & $\begin{array}{l}\text { Sup D } \\
0.000\end{array}$ \\
\hline Perf & 0.187 & 0.376 & 0.235 & 0.373 & 0.115 & 0.230 & 0.167 & 0.000 & 0.000 & 0.000 & 0.000 & 0.000 & 0.000 & 0.000 & 0.000 & 0.000 & 0.000 \\
\hline Rel & 0.228 & 0.149 & 0.118 & 0.187 & 0.230 & 0.070 & 0.096 & 0.000 & 0.000 & 0.000 & 0.000 & 0.000 & 0.000 & 0.000 & 0.000 & 0.000 & 0.000 \\
\hline Price & 0.117 & 0.192 & 0.118 & 0.187 & 0.053 & 0.121 & 0.301 & 0.000 & 0.000 & 0.000 & 0.000 & 0.000 & 0.000 & 0.000 & 0.000 & 0.000 & 0.000 \\
\hline Serv & 0.183 & 0.071 & 0.235 & 0.098 & 0.257 & 0.230 & 0.103 & 0.000 & 0.000 & 0.000 & 0.000 & 0.000 & 0.000 & 0.000 & 0.000 & 0.000 & 0.000 \\
\hline Noises & 0.132 & 0.133 & 0.235 & 0.057 & 0.115 & 0.230 & 0.050 & 0.000 & 0.000 & 0.000 & 0.000 & 0.000 & 0.000 & 0.000 & 0.000 & 0.000 & 0.000 \\
\hline COM & 0.153 & 0.079 & 0.059 & 0.098 & 0.230 & 0.121 & 0.283 & 0.000 & 0.000 & 0.000 & 0.000 & 0.000 & 0.000 & 0.000 & 0.000 & 0.000 & 0.000 \\
\hline$P \& T$ & 0.000 & 0.045 & 0.261 & 0.458 & 0.300 & 0.394 & 0.271 & 0.238 & 0.342 & 0.238 & 0.182 & 0.124 & 0.140 & 0.000 & 0.000 & 0.000 & 0.000 \\
\hline Toler & 0.000 & 0.043 & 0.119 & 0.074 & 0.100 & 0.394 & 0.070 & 0.111 & 0.171 & 0.000 & 0.048 & 0.124 & 0.081 & 0.000 & 0.000 & 0.000 & 0.000 \\
\hline Output & 0.000 & 0.322 & 0.000 & 0.091 & 0.000 & 0.000 & 0.000 & 0.425 & 0.000 & 0.463 & 0.334 & 0.234 & 0.520 & 0.000 & 0.000 & 0.000 & 0.000 \\
\hline Rep & 0.000 & 0.098 & 0.523 & 0.091 & 0.600 & 0.000 & 0.524 & 0.052 & 0.342 & 0.119 & 0.334 & 0.124 & 0.000 & 0.000 & 0.000 & 0.000 & 0.000 \\
\hline Used RM & 0.000 & 0.169 & 0.097 & 0.155 & 0.000 & 0.137 & 0.135 & 0.111 & 0.054 & 0.119 & 0.102 & 0.395 & 0.000 & 0.000 & 0.000 & 0.000 & 0.000 \\
\hline Cons & 0.000 & 0.322 & 0.000 & 0.131 & 0.000 & 0.075 & 0.000 & 0.062 & 0.091 & 0.061 & 0.000 & 0.000 & 0.260 & 0.000 & 0.000 & 0.000 & 0.000 \\
\hline upplier A & 0.000 & 0.000 & 0.000 & 0.000 & 0.000 & 0.000 & 0.000 & 0.333 & 0.079 & 0.125 & 0.088 & 0.089 & 0.200 & 0.286 & 0.231 & 0.222 & 0.235 \\
\hline upplier B & 0.000 & 0.000 & 0.000 & 0.000 & 0.000 & 0.000 & 0.000 & 0.167 & 0.269 & 0.125 & 0.272 & 0.648 & 0.100 & 0.286 & 0.231 & 0.222 & 0.059 \\
\hline upplier $C$ & 0.000 & 0.000 & 0.000 & 0.000 & 0.000 & 0.000 & 0.000 & 0.167 & 0.573 & 0.250 & 0.483 & 0.089 & 0.100 & 0.143 & 0.462 & 0.111 & 0.235 \\
\hline uppli & $\mathrm{L}_{0.000}$ & 0.000 & 0.000 & 0.000 & 0.000 & 0.000 & 0.000 & 0.333 & 0.079 & 0.500 & 0.157 & 0.173 & 0.600 & 0.286 & 0.077 & 0.444 & 0.471 \\
\hline
\end{tabular}

8. The best supplier

Now, the main question of this study has to be answered: 'which supplier is the best?'

To answer the question, a few more calculations are required as follows.

1. Computing $W_{A}$

$$
\begin{aligned}
& W_{A}=W_{P R-P R} \cdot W_{P R-C N} \quad \text { Eq. (15) } \\
& \text { Perf Rel Price Serv Noises CoM } \\
& \begin{array}{c}
\text { P\&T } \\
\text { Toler } \\
\text { Rep } \\
\text { Used RM } \\
\operatorname{Rens} \\
\operatorname{Cons}
\end{array}\left[\begin{array}{llllll}
0.186 & 0.210 & 0.210 & 0.215 & 0.256 & 0.201 \\
0.064 & 0.086 & 0.098 & 0.079 & 0.134 & 0.084 \\
0.408 & 0.309 & 0.372 & 0.328 & 0.239 & 0.322 \\
0.109 & 0.241 & 0.109 & 0.250 & 0.172 & 0.230 \\
0.110 & 0.027 & 0.075 & 0.028 & 0.080 & 0.023
\end{array}\right] \text { Matrix (17) }
\end{aligned}
$$

2. Computing $W_{B}$

$$
W_{B}=W_{S-S} \cdot W_{S-P R} \quad \text { Eq. (16) }
$$

To cite this document: Asadabadi, M. R. (2017). A customer based supplier selection process that combines quality function deployment, the analytic network process and a Markov chain. European Journal of Operational Research, 263(3), 1049-1062. 


$$
\begin{aligned}
& \text { P\&T Toler Output Rel Used RM Cons } \\
& W_{B}=\begin{array}{rlllll}
\text { Supplier A } \\
\text { Supplier B C }
\end{array} \quad\left[\begin{array}{llllll}
0.249 & 0.231 & 0.238 & 0.232 & 0.236 & 0.244 \\
0.190 & 0.217 & 0.150 & 0.204 & 0.205 & 0.138 \\
0.221 & 0.218 & 0.221 & 0.229 & 0.362 & 0.227 \\
0.339 & 0.335 & 0.392 & 0.335 & 0.197 & 0.392
\end{array}\right] \text { Matrix (18) }
\end{aligned}
$$

3. $\quad$ Computing $W_{C}$

$$
\begin{aligned}
& W_{C}=W_{C N-C N} \cdot W_{C N} \quad \text { Eq. (17) } \\
& \left.W_{C}=\begin{array}{rr}
\text { Perf } & 0.245 \\
\text { Rel } & 0.142 \\
\text { Price } & 0.156 \\
\text { Serv } & 0.171 \\
\text { Noises } & 0.144 \\
\text { COM } & 0.141
\end{array}\right]
\end{aligned}
$$

4. $\quad$ Computing $W_{D}$

$$
\begin{aligned}
& W_{D}=W_{A} \cdot W_{C} \quad \text { Eq. (18) }
\end{aligned}
$$

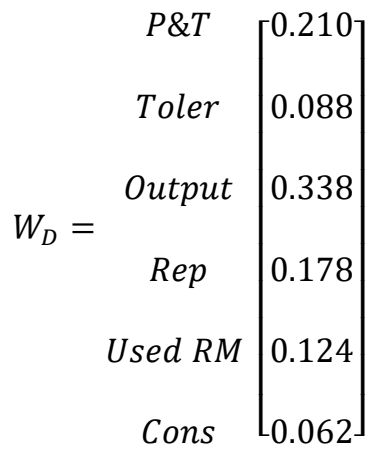

5. $\quad$ Finding the best supplier

$$
\begin{aligned}
& W_{A N P}=W_{B} \cdot W_{D} \text { Eq. (19) } \\
& W_{A N P}=\begin{array}{r}
\text { Supplier } A \\
\text { Supplier } B \\
\text { Supplier } C
\end{array}\left[\begin{array}{l}
0.239 \\
0.180 \\
0.240 \\
\text { Supplier } D
\end{array}\right] \text { Matrix (21): The final ranking of suppliers }
\end{aligned}
$$

Based on the results of the proposed method, performance of the motor is the most important $\mathrm{CN}$, and the output of the motor is the most important PR. Thus, based on suppliers' qualifications and the relevant computations, it turns out that to keep customers satisfied, supplier D is the best supplier for the company.

\section{Discussion}

To cite this document: Asadabadi, M. R. (2017). A customer based supplier selection process that combines quality function deployment, the analytic network process and a Markov chain. European Journal of Operational Research, 263(3), 1049-1062. 
Selecting the best supplier is a complex issue and has a significant impact on the effectiveness and efficiency of companies (Bohner \& Minner, 2017; Rao et al., 2017). It is a multi-criteria decision making problem (Govindan et al., 2015). Given the significance of this MCDM problem (Sevkli, 2010), many tools and techniques have been developed to deal with it (Asadabadi, 2014).

Since quality is the most important factor in dealing with supplier selection (K. Chen \& Chen, 2006; Tavana, Yazdani, \& Di Caprio, 2017), and quality is a summary of customer 'wants', a novel customer based method was designed to make the selection process on the basis of customer desires. The HOQ was developed by Akao (1972) and technically started being used in Japan (Mehrjerdi, 2010). It is the main tool of QFD and acts like a translator. This tool is capable of translating the importance vectors of one set of elements to another set. Therefore, it was employed to relate CNs (adjusted with a Markov chain), PRs, and suppliers' qualifications. For rating and scoring the criteria, the widely used 1 to 9 scale (Saaty, 1977, 1986, 1990) was applied.

In this study the ANP was utilized rather than the AHP even though the AHP is a more tested and examined process. There are many examples of applying the AHP for the supplier selection process. Nydick and Hill (1992) applied the AHP to structure the process of selecting a supplier. The criteria went through the process of pairwise comparisons. Four suppliers were compared with respect to four criteria: quality, price, service, and delivery. Although the flow of their proposed model seemed to be logical, it failed to consider interrelations between quality, price, service, and delivery. It does not seem reasonable to study and rank, for example quality and service, without considering their inherent influences on each other. Since the AHP is inherently incapable of taking interrelations into account (Kuo \& Lin, 2012), the same problem seems to exist in most of the other AHP applications for the supplier selection problem (Asamoah, Annan, \& Nyarko, 2012; Azadnia, Saman, \& Wong, 2015; Chan, Kumar, Tiwari, Lau, \& Choy, 2008; Chan et al., 2008b; Kahraman et al., 2003; Labib, 2011; Lorentz et al., 2012; Sivrikaya, Kaya, Dursun, \& Çebi, 2015). The ANP benefits from a nonlinear structure that derives composite priorities to determine the relative measurements. Partovi (2001) highlights an interesting example of internal dependencies by Saaty and Takizawa (1986) as follows. In designing a motorcycle, there are various functions to consider but they are not independent. For example turning is influenced by stopping, running, accelerating as well as turning itself. There are a limited number of papers dealing with the interrelations among the supplier selection criteria (Kasirian \& Yusuff, 2010; Ozaki et al., 2012; Kuo \& Lin, 2012; Huang \& Hu, 2013). Thus, in the study the ANP rather than AHP was applied in order to take into account the interrelations of the elements of the HOQ while the translation was being processed.

Customer needs change as time passes. A CN which initially is identified to be the most important $\mathrm{CN}$ for a customer may lose some of its importance over time; however, further down the line it may again become the most important CN. For example, a customer who buys a particular type of bread, not every time buys the same loaf of bread. The change in preference might be with respect to the shape, ingredients, brand, and so on. Despite these changes the bakeries experience, more or less, a similar consumption pattern is observed in their bakeries every day. This is very similar to the process of Markov chains. Markov chains are stochastic models which are capable of modeling, mathematically, real world processes (Lehoczky, 1980). They are capable of tracing, predicting and suggesting a pattern of constantly-changing-processes (Norris, 1998). A Markov chain can be utilized to work in combination with the ANP-QFD. It was applied here to trace $\mathrm{CN}$ priorities and find a pattern for them. The HOQ was fed with a pattern of changing $\mathrm{CN}$ priorities which was generated through a Markov chain process instead of the initial CNs. The importance of the acquired pattern is that it is independent of the initial CNs, so there is no need to continuously obtain $\mathrm{CN}$ priorities which could mean introducing a different supplier at each time of application. By applying this approach, only one supplier is found as the best supplier, irrespective of constantly-changing CNs.

A review of the previous studies reveals that the Markov chain is new to the conceptualization of quality management and has not previously been applied to address the supplier selection problem. There are only three relevant papers: Wu \& Shieh, (2006, 2008) and Asadabadi (2016). Wu \& Shieh (2008) investigated the relations between CNs and PRs by applying a Markov chain. They considered different market situations as Markov states where the probabilities of transitioning from one market situation to another were predetermined. Some aspects of their study can be improved. First, they focused on analyzing the relations between the elements while CNs remained the same. They ignored the possibility of change in $\mathrm{CN}$ priorities while tracing the relationship between the elements of the HOQ. Not only does the assumption of having that level of dynamic change in relations, along with the assumption of stability in $\mathrm{CN}$ priorities, seems unreasonable, but also the inverse seems reasonable: $\mathrm{CN}$ priorities are changing, but the relations between the elements do not significantly change. Second, their proposed model ignores the interrelations between the elements of the HOQ. This ignorance can be addressed by using ANP rather than AHP. In their other To cite this document: Asadabadi, M. R. (2017). A customer based supplier selection process that combines quality function deployment, the analytic network process and a Markov chain. European Journal of Operational Research, 263(3), 1049-1062. 
paper (Wu \& Shieh, 2008), they applied a hidden Markov chain model to develop another version of their previous approach, but the highlighted issues remain untouched. A recent study by Asadabadi (2016) proposed a Markovian ANP-QFD approach and the efficiency of this new approach needs to be examined in different areas of decision making. This paper applies this method to address the supplier selection problem by proposing a customer based supplier selection method. Still further studies should assess the applicability of the Markovian ANP-QFD in other areas of decision making or extend the current research to include such as green criteria, by proposing a green customer based supplier selection approach that applies the Markovian ANP-QFD method.

\section{Conclusion}

In summary, the success of companies depends greatly on their level of customer satisfaction. This knowledge has meant many companies align their performance components as well as their decisions with their customers' desires. The quality of the final product is a determining factor in customer satisfaction, and it is strongly influenced by products or services supplied. It is necessary, then, to design a customer based supplier selection method. Connecting the supplier selection process to customer needs encourages suppliers to focus on meeting the needs of the final customers. In this study, the Markovian-ANP-QFD method was applied to address the supplier selection problem. The method considers a network of relations and interrelations between CNs, PRs, and suppliers' qualifications in a QFD based structure. Suppliers then are ranked and the best one is selected. When comparing with the simple ANPQFD, since the supplier selection here is based on the pattern of the CNs rather than the initial CNs, this method is more supportive of establishing a long-term relationship with suppliers. Further studies should examine challenges in employing the Markovian-ANP-QFD in other areas of decision making.

\section{References}

Adamcsek, E. (2008). The analytic hierarchy process and its generalizations. Eotvos Lorand University.

Ahmadi, H. B., Petrudi, S. H. H., \& Wang, X. (2016). Integrating sustainability into supplier selection with analytical hierarchy process and improved grey relational analysis: a case of telecom industry. The International Journal of Advanced Manufacturing Technology, 1-15.

Ahn, B. S. (2017). The analytic hierarchy process with interval preference statements. Omega, 67, 177-185.

Akao, Y. (1972). New product development and quality assurance-quality deployment system. Standardization and Quality Control, 25(4), 7-14.

Asadabadi, M. (2014). A Hybrid QFD-based approach in addressing supplier selection problem in product improvement process. International Journal of Industrial Engineering Computations, 5(4), 543.

Asadabadi, M. R. (2016). A Markovian-QFD Approach in Addressing the Changing Priorities of the Customer Needs. International Journal of Quality \& Reliability Management, 33(8), null. doi:doi:10.1108/IJQRM-07-2014-0091

Asamoah, D., Annan, J., \& Nyarko, S. (2012). AHP approach for supplier evaluation and selection in a pharmaceutical manufacturing firm in Ghana. International Journal of Business and Management, 7(10), 49.

Ayă̆, Z., Samanlioglu, F., \& Büyüközkan, G. (2013). A fuzzy QFD approach to determine supply chain management strategies in the dairy industry. Journal of Intelligent Manufacturing, 24(6), 1111-1122.

Azadnia, A. H., Saman, M. Z. M., \& Wong, K. Y. (2015). Sustainable supplier selection and order lot-sizing: an integrated multiobjective decision-making process. International Journal of Production Research, 53(2), 383-408.

Bayazit, O. (2006). Use of analytic network process in vendor selection decisions. Benchmarking: An International Journal, 13(5), $566-579$.

Baumann, H., \& Sandmann, W. (2017). Multi-server tandem queue with Markovian arrival process, phase-type service times, and finite buffers. European Journal of Operational Research, 256(1), 187-195.

Berthiaux, H., Marikh, K., Mizonov, V., Ponomarev, D., \& Barantzeva, E. (2004). Modeling continuous powder mixing by means of the theory of Markov chains. Particulate Science and Technology, 22(4), 379-389.

Bhattacharya, A., Geraghty, J., \& Young, P. (2010). Supplier selection paradigm: An integrated hierarchical QFD methodology under multiple-criteria environment. Applied Soft Computing, 10(4), 1013-1027.

Bhattacharya, A., Sarkar*, B., \& Mukherjee, S. K. (2005). Integrating AHP with QFD for robot selection under requirement perspective. International Journal of Production Research, 43(17), 3671-3685.

Bohner, C., \& Minner, S. (2017). Supplier selection under failure risk, quantity and business volume discounts. Computers \& Industrial Engineering, 104, 145-155.

Brodsky, E., \& Darkhovsky, B. S. (2013). Nonparametric methods in change point problems (Vol. 243). Springer Science \&

Business Media.

Büyüközkan, G., \& Berkol, Ç. (2011). Designing a sustainable supply chain using an integrated analytic network process and goal programming approach in quality function deployment. Expert Systems with Applications, 38(11), 13731-13748.

Büyüközkan, G., \& Göçer, F. (2017). Application of a new combined intuitionistic fuzzy MCDM approach based on axiomatic design methodology for the supplier selection problem. Applied Soft Computing, 52, 1222-1238.

To cite this document: Asadabadi, M. R. (2017). A customer based supplier selection process that combines quality function deployment, the analytic network process and a Markov chain. European Journal of Operational Research, 263(3), 1049-1062. 
Celik, M., Cebi, S., Kahraman, C., \& Er, I. D. (2009). An integrated fuzzy QFD model proposal on routing of shipping investment decisions in crude oil tanker market. Expert Systems with Applications, 36(3), 6227-6235.

Chai, J., Liu, J. N., \& Ngai, E. W. (2013). Application of decision-making techniques in supplier selection: A systematic review of literature. Expert Systems with Applications, 40(10), 3872-3885.

Chan, F. T., Kumar, N., Tiwari, M., Lau, H., \& Choy, K. (2008). Global supplier selection: a fuzzy-AHP approach. International Journal of Production Research, 46(14), 3825-3857.

Chen, K., \& Chen, K. (2006). Supplier selection by testing the process incapability index. International Journal of Production Research, 44(3), 589-600.

Chen, L.-H., Ko, W.-C., \& Yeh, F.-T. (2017). Approach based on fuzzy goal programing and quality function deployment for new product planning. European Journal of Operational Research, 259(2), 654-663.

Chen, S., Yang, C., Lin, W., Yeh, T., \& Lin, Y. (2007). Construction of key model for knowledge management system using AHPQFD for semiconductor industry in Taiwan. Journal of Manufacturing Technology Management, 18(5), 576-597.

Cheng, C.-J., Chiu, S., Cheng, C.-B., \& Wu, J.-Y. (2012). Customer lifetime value prediction by a Markov chain based data mining model: Application to an auto repair and maintenance company in Taiwan. Scientia Iranica, 19(3), 849-855.

Chin, K.-S., Wang, Y.-M., Yang, J.-B., \& Poon, K. K. G. (2009). An evidential reasoning based approach for quality function deployment under uncertainty. Expert Systems with Applications, 36(3), 5684-5694.

De Cooman, G., Hermans, F., \& Quaeghebeur, E. (2009). Imprecise Markov chains and their limit behavior. Probability in the Engineering and Informational Sciences, 23(4), 597.

Enriquez, F. T., Osuna, A. J., \& Bosch, V. G. (2004). Prioritising customer needs at spectator events: Obtaining accuracy at a difficult QFD arena. International Journal of Quality \& Reliability Management, 21(9).

Farran, M., \& Zayed, T. (2009). Comparative analysis of life-cycle costing for rehabilitating infrastructure systems. Journal of Performance of Constructed Facilities, 23(5), 320-326.

Goetsch, D. L., \& Davis, S. B. (2014). Quality management for organizational excellence: pearson.

Govindan, K., Rajendran, S., Sarkis, J., \& Murugesan, P. (2015). Multi criteria decision making approaches for green supplier evaluation and selection: a literature review. Journal of Cleaner Production, 98, 66-83.

Gölgeci, I., Murphy, W. H., \& Johnston, D. A. (2017). Power-based behaviors in supply chains and their effects on relational satisfaction: A fresh perspective and directions for research. European Management Journal.

Han, S. B., Chen, S. K., Ebrahimpour, M., \& Sodhi, M. S. (2001). A conceptual QFD planning model. International Journal of Quality \& Reliability Management, 18(8), 796-812.

Hanumaiah, N., Ravi, B., \& Mukherjee, N. (2006). Rapid hard tooling process selection using QFD-AHP methodology. Journal of Manufacturing Technology Management, 17(3), 332-350.

Haq, A. N., \& Boddu, V. (2017). Analysis of enablers for the implementation of leagile supply chain management using an integrated fuzzy QFD approach. Journal of Intelligent Manufacturing, 28(1), 1-12.

Hsu, T.-H., \& Lin, L.-Z. (2006). QFD with fuzzy and entropy weight for evaluating retail customer values. Total Quality Management \& Business Excellence, 17(7), 935-958.

Iqbal, Z., P. Grigg, N., Govinderaju, K., \& Campbell-Allen, N. (2014). Statistical comparison of final weight scores in quality function deployment (QFD) studies. International Journal of Quality \& Reliability Management, 31(2), 184-204.

Iranmanesh, H., \& Tabrizi, B. H. (2009). An integrated framework for customer-oriented web design using QFD, Kano model and ANP. Paper presented at the Computers \& Industrial Engineering, 2009. CIE 2009. International Conference on.

Jacques, M., Baccarani, C., Andronikidis, A., Georgiou, A. C., Gotzamani, K., \& Kamvysi, K. (2009). The application of quality function deployment in service quality management. The TQM Journal, 21(4), 319-333.

Kahraman, C., Cebeci, U., \& Ulukan, Z. (2003). Multi-criteria supplier selection using fuzzy AHP. Logistics information management, 16(6), 382-394.

Kamvysi, K., Gotzamani, K., Andronikidis, A., \& Georgiou, A. C. (2014). Capturing and prioritizing students' requirements for course design by embedding Fuzzy-AHP and linear programming in QFD. European Journal of Operational Research, 237(3), 1083-1094.

Kamvysi, K., Gotzamani, K., Georgiou, A. C., \& Andronikidis, A. (2010). Integrating DEAHP and DEANP into the quality function deployment. The TQM Journal, 22(3), 293-316.

Karsak, E. E., \& Dursun, M. (2015). An integrated fuzzy MCDM approach for supplier evaluation and selection. Computers \& Industrial Engineering, 82, 82-93.

Karsak, E. E., Sozer, S., \& Alptekin, S. E. (2003). Product planning in quality function deployment using a combined analytic network process and goal programming approach. Computers \& Industrial Engineering, 44(1), 171-190.

Kumar Kar, A., \& K. Pani, A. (2014). Exploring the importance of different supplier selection criteria. Management Research Review, 37(1), 89-105.

Kuo, R. J., \& Lin, Y. J. (2012). Supplier selection using analytic network process and data envelopment analysis. International Journal of Production Research, 50(11), 2852-2863.

Kutschenreiter-Praszkiewicz, I. (2013). Application of neural network in QFD matrix. Journal of Intelligent Manufacturing, 24(2), 397-404.

Labib, A. W. (2011). A supplier selection model: a comparison of fuzzy logic and the analytic hierarchy process. International Journal of Production Research, 49(21), 6287-6299.

Lam, K., \& Zhao, X. (1998). An application of quality function deployment to improve the quality of teaching. International Journal of Quality \& Reliability Management, 15(4), 389-413.

To cite this document: Asadabadi, M. R. (2017). A customer based supplier selection process that combines quality function deployment, the analytic network process and a Markov chain. European Journal of Operational Research, 263(3), 1049-1062. 
Li, S., \& Kuo, X. (2007). The enhanced quality function deployment for developing virtual items in massive multiplayer online role playing games. Computers \& Industrial Engineering, 53(4), 628-641.

Lin, C.-Y., Lee, A. H., \& Kang, H.-Y. (2015). An integrated new product development framework-an application on green and low-carbon products. International Journal of Systems Science, 46(4), 733-753.

Lin, Y., Cheng, H.-P., Tseng, M.-L., \& Tsai, J. C. (2010). Using QFD and ANP to analyze the environmental production requirements in linguistic preferences. Expert Systems with Applications, 37(3), 2186-2196.

Liu, A., Hu, H., Zhang, X., \& Lei, D. (2017). Novel Two-Phase Approach for Process Optimization of Customer Collaborative Design Based on Fuzzy-QFD and DSM. IEEE Transactions on Engineering Management.

Liu, C.-H., Chiu, C.-L., \& Chiu, S.-C. (2011). Analyze dynamic value of strategic partners using Markov chain. Expert Systems with Applications, 38(11), 13563-13567.

Liu, W., Shen, X., \& Xie, D. (2017). Decision Method for the Optimal Number of Logistics Service Providers with Service Quality Guarantee and Revenue Fairness. Applied Mathematical Modelling.

Lorentz, H., Shi, Y., Hilmola, O.-P., Jagjit Singh Srai, D., Punniyamoorty, M., Mathiyalagan, P., \& Lakshmi, G. (2012). A combined application of structural equation modeling (SEM) and analytic hierarchy process (AHP) in supplier selection. Benchmarking: An International Journal, 19(1), 70-92.

Lu, S.-L. (2012). Assessing the credit risk of bank loans using an extended Markov chain model. Journal of Applied Finance and Banking, 2(1), 197.

Marttunen, M., Lienert, J., \& Belton, V. (2017). Structuring problems for Multi-Criteria Decision Analysis in Practice: A Literature Review of Method Combinations. European Journal of Operational Research.

Mayyas, A., Shen, Q., Mayyas, A., Shan, D., Qattawi, A., \& Omar, M. (2011). Using quality function deployment and analytical hierarchy process for material selection of body-in-white. Materials \& Design, 32(5), 2771-2782.

Miller, G. A. (1956). The magical number seven, plus or minus two: some limits on our capacity for processing information. Psychological review, 63(2), 81.

Nazari-Shirkouhi, S., \& Keramati, A. (2017). Modeling customer satisfaction with new product design using a flexible fuzzy regression-DEA algorithm. Applied Mathematical Modelling.

Ni, M., Xu, X., \& Deng, S. (2007). Extended QFD and data-mining-based methods for supplier selection in mass customization. International Journal of Computer Integrated Manufacturing, 20(2-3), 280-291.

Okur, A., Nasibov, E. N., Kiliç, M., \& Yavuz, M. (2009). Using OWA aggregation technique in QFD: a case study in education in a textile engineering department. Quality \& Quantity, 43(6), 999-1009.

Pal, D., Ravi, B., \& Bhargava, L. (2007). Rapid tooling route selection for metal casting using QFD-ANP methodology. International Journal of Computer Integrated Manufacturing, 20(4), 338-354.

Partovi, F. Y. (2001). An analytic model to quantify strategic service vision. International Journal of Service Industry Management, $12(5), 476-499$.

Partovi, F. Y. (2007). An analytical model of process choice in the chemical industry. International Journal of Production Economics, 105(1), 213-227.

Partovi, F. Y., \& Corredoira, R. A. (2002). Quality function deployment for the good of soccer. European Journal of Operational Research, 137(3), 642-656.

Pourmoayed, R., Nielsen, L. R., \& Kristensen, A. R. (2016). A hierarchical Markov decision process modeling feeding and marketing decisions of growing pigs. European Journal of Operational Research, 250(3), 925-938.

Qin, J., Liu, X., \& Pedrycz, W. (2017). An extended TODIM multi-criteria group decision making method for green supplier selection in interval type-2 fuzzy environment. European Journal of Operational Research, 258(2), 626-638.

Raharjo, H., Brombacher, A. C., \& Xie, M. (2008). Dealing with subjectivity in early product design phase: A systematic approach to exploit Quality Function Deployment potentials. Computers \& Industrial Engineering, 55(1), 253-278.

Raharjo, H., Xie, M., \& Brombacher, A. (2006). Prioritizing quality characteristics in dynamic quality function deployment. International Journal of Production Research, 44(23), 5005-5018.

Raharjo, H., Xie, M., \& Brombacher, A. C. (2011). A systematic methodology to deal with the dynamics of customer needs in Quality Function Deployment. Expert Systems with Applications, 38(4), 3653-3662.

Rao, C., Xiao, X., Goh, M., Zheng, J., \& Wen, J. (2017). Compound Mechanism Design of Supplier Selection Based on Multiattribute Auction and Risk Management of Supply Chain. Computers \& Industrial Engineering.

Saaty, T. L. (1977). A scaling method for priorities in hierarchical structures. Journal of mathematical psychology, 15(3), $234-281$.

Saaty, T. L. (1986). Axiomatic foundation of the analytic hierarchy process. Management Science, 32(7), 841-855.

Saaty, T. L. (1990). How to make a decision: the analytic hierarchy process. European Journal of Operational Research, 48(1), 926.

Saaty, T. L. (1996). Decision making with dependence and feedback: The analytic network process (Vol. 4922): RWS publications Pittsburgh.

Saaty, T. L. (1999). Fundamentals of the analytic network process. Paper presented at the Proceedings of the 5th international symposium on the analytic hierarchy process.

Saaty, T. L., \& Takizawa, M. (1986). Dependence and independence: From linear hierarchies to nonlinear networks. European Journal of Operational Research, 26(2), 229-237.

Sampaio, M. S. C., Ana Cristina Fernandes, P., Cagnin, F., Oliveira, M. C., Simon, A. T., Helleno, A. L., \& Vendramini, M. P. (2016a. Proposal of a method for selecting suppliers considering risk management: An application at the automotive industry. International Journal of Quality \& Reliability Management, 33(4), 488-498.

To cite this document: Asadabadi, M. R. (2017). A customer based supplier selection process that combines quality function deployment, the analytic network process and a Markov chain. European Journal of Operational Research, 263(3), 1049-1062. 
Satty, T. L. (1996). Decision making with dependence and feedback: The analytic network process. RWS Publication.

Satty, T. L. (1999). Fundamentals of the Analytic network Process. Paper presented at the Japan, Kobe: The International Symposium on the Analytic Hierarchy Process.

Sevkli, M. (2010). An application of the fuzzy ELECTRE method for supplier selection. International Journal of Production Research, 48(12), 3393-3405.

Sharma, J., \& Rawani, A. (2007). Ranking customer requirements in QFD by factoring in their interrelationship values. The Quality Management Journal, 14(4), 53.

Singer, P., Helic, D., Taraghi, B., \& Strohmaier, M. (2014). Detecting memory and structure in human navigation patterns using markov chain models of varying order. PloS one, 9(7), e102070.

Sivasamy, K., Arumugam, C., Devadasan, S., Murugesh, R., \& Thilak, V. (2016). Advanced models of quality function deployment: a literature review. Quality \& Quantity, 50(3), 1399-1414.

Sivrikaya, B. T., Kaya, A., Dursun, E., \& Çebi, F. (2015). Fuzzy AHP-goal programming approach for a supplier selection problem. Research in Logistics and Production, 5(3), 271-285.

Sodenkamp, M. A., Tavana, M., \& Di Caprio, D. (2016). Modeling synergies in multi-criteria supplier selection and order allocation: An application to commodity trading. European Journal of Operational Research, 254(3), 859-874.

Tavana, M., Yazdani, M., \& Di Caprio, D. (2017). An application of an integrated ANP-QFD framework for sustainable supplier selection. International Journal of Logistics Research and Applications, 20(3), 254-275.

Viswanadham, N., \& Samvedi, A. (2013). Supplier selection based on supply chain ecosystem, performance and risk criteria. International Journal of Production Research, 51(21), 6484-6498.

Wang, Y.-M. (2012). Assessing the relative importance weights of customer requirements using multiple preference formats and nonlinear programming. International Journal of Production Research, 50(16), 4414-4425.

Wang, Y.-M., \& Chin, K.-S. (2011). A linear goal programming approach to determining the relative importance weights of customer requirements in quality function deployment. Information Sciences, 181(24), 5523-5533.

Wu, H.-H., Liao, A., \& Wang, P.-C. (2005). Using grey theory in quality function deployment to analyse dynamic customer requirements. The International Journal of Advanced Manufacturing Technology, 25(11-12), 1241-1247.

Wu, H.-H., \& Shieh, J.-I. (2006). Using a Markov chain model in quality function deployment to analyse customer requirements. The International Journal of Advanced Manufacturing Technology, 30(1-2), 141-146.

Wu, H.-H., \& Shieh, J.-I. (2008). Applying a Markov chain model in quality function deployment. Quality \& Quantity, 42(5), 665678.

Xie, M., Goh, T. N., \& Kuralmani, V. (2012). Statistical models and control charts for high-quality processes. Springer Science \& Business Media.

Xie, C., Anumba, C. J., Lee, T.-R., Ho, W., Dey, P. K., \& Lockström, M. (2011). Strategic sourcing: a combined QFD and AHP approach in manufacturing. Supply Chain Management: An International Journal, 16(6), 446-461.

Yazdani, M., Chatterjee, P., Zavadskas, E. K., \& Zolfani, S. H. (2017). Integrated QFD-MCDM framework for green supplier selection. Journal of Cleaner Production, 142, 3728-3740.

Yu, W., Sheblé, G. B., \& Matos, M. A. (2006). Application of Markov chain models for short-term generation assets valuation. Probability in the Engineering and Informational Sciences, 20(01), 127-141.

Zare Mehrjerdi, Y. (2010). Quality function deployment and its extensions. International Journal of Quality \& Reliability Management, 27(6), 616-640.

To cite this document: Asadabadi, M. R. (2017). A customer based supplier selection process that combines quality function deployment, the analytic network process and a Markov chain. European Journal of Operational Research, 263(3), 1049-1062. 